1 van Os J. Psychotic experiences: disadvantaged and different from the norm Br J Psychiatry 2012; 201: 258-9.

2 Das-Munshi J, Bécares L, Boydell JE, Dewey ME, Morgan C, Stansfeld SA, et al. Ethnic density as a buffer for psychotic experiences: findings from a national survey (EMPIRIC). Br J Psychiatry 2012; 201: 282-90.

3 Das-Munshi J, Bécares L, Dewey ME, Stansfeld SA, Prince MJ. Understanding the effect of ethnic density on mental health: multi-level investigation of survey data from England. BMJ 2010; 341: 9

4 Rothman KJ, Greenland S. Causation and causal inference in epidemiology. Am J Public Health 2005; 95: S144-50.

5 Gardner MJ, Altman DG. Confidence intervals rather than P values: estimation rather than hypothesis testing. BMJ 1986; 292: 746-50.

Jayati Das-Munshi, Department of Health Service and Population Research, Institute of Psychiatry, King's College London, UK. Email: jayati.das-munshi@kcl.ac.uk; Laia Bécares, Cathie Marsh Centre for Census and Survey Research, School of Social Services, University of Manchester; Jane E. Boydell, Psychological Medicine, Michael E. Dewey, Craig Morgan, Department of Health Service and Population Research, Institute of Psychiatry, King's College London; Stephen A. Stansfeld Wolfson Institute for Preventive Medicine, Centre for Psychiatry, Queen Mary University of London, Barts and the London School of Medicine; Martin J. Prince Department of Health Service and Population Research, Institute of Psychiatry, King's College London, UK

doi: 10.1192/bjp.202.3.237a

\section{Identifying treatment-resistant schizophrenia}

I was surprised to read the paper of Howes et al. ${ }^{1}$ No control group was investigated. This paper implies that any patient for whom a third antipsychotic is considered ought to be considered for clozapine, and if they are not started on clozapine, this constitutes an unacceptable delay.

Such a sweeping assumption cannot be verified without the inclusion of a group of preferably contemporaneous control patients of approximately the same age, gender, diagnosis and treatment duration, who were treated with a third antipsychotic drug, but who did not go on to receive clozapine. Merely the existence of such a group verifies that the delay is indeed theoretical. How are those who will go on to need clozapine be identified? One cannot predict the future, stating with confidence that all patients on a third antipsychotic will require clozapine eventually. The paper is silent on these consequential issues.

This obvious limitation is not mentioned by the authors in their critique of their methodology. Neither does Patel's editorial commentary remark on it. ${ }^{2}$

I emphasise that I agree with the authors, that delay in initiating clozapine does many patients a great disservice. I have been one of the UK's major users of and proponents of clozapine since 1990, and recently published on clinical use of clozapine in Advances in Psychiatric Treatment. ${ }^{3}$ I still, regularly, encounter patients who should have been started on clozapine much longer than 4 years ago. The trouble is, the longer this treatment decision is ignored or put off, the more reluctance there seems to be. Nevertheless, there remain a number of alternative strategies to address those contributors to unsatisfactory response to antipsychotic drugs, such as poor adherence, substance misuse and intolerance, which may not necessarily succumb to clozapine treatment.

1 Howes OD, Vergunst F, Gee S, McGuire P, Kapur S, Taylor D. Adherence to treatment guidelines in clinical practice: study of antipsychotic treatment prior to clozapine initiation. Br J Psychiatry 2012; 201: 481-5.

2 Patel MX. Clinician hesitation prior to clozapine initiation: is it justifiable? $\mathrm{Br} \mathrm{J}$ Psychiatry 2012; 201: 425-7.

3 Mortimer AM. Using clozapine in clinical practice. Adv Psychiatr Treat 2011; 17: $256-65$.

Ann Mortimer, Consultant Psychiatrist, NAViGO, The Eleanor Centre, Grimsby، North East Lincolnshire, and Emeritus Professor, Hull University, UK. Email. ann.mortimer@nhs.net

doi: 10.1192/bjp.202.3.238
Authors' reply: We thank Professor Mortimer for raising some important issues. The first is about the absence of a control group. Our study was observational, designed to determine clinical practice in antipsychotic prescribing prior to clozapine relative to treatment guidelines, which is why there is no control group. Prescribing in patients who have treatment-refractory illnesses but have never received clozapine is an important issue but outside the scope of our study. The second issue was that the paper implies that any patient for whom a third antipsychotic is considered ought to be considered for clozapine. Our study specifically selected patients who went on to be prescribed clozapine, predominantly because the illness was treatment refractory (see p. 481). ${ }^{1}$ As such, it is relevant to patients with treatment-refractory illness, and in no way should be taken to imply that all patients who are being considered for a third antipsychotic should automatically be considered for clozapine. It is important to note that our design could not confirm the illness was treatment refractory at the point at which two antipsychotics had been used and, although treatment resistance can be evident from the first episode, ${ }^{2}$ it may potentially emerge later in some patients (this is discussed further in the paper, p. $483^{1}$ ). For this reason, the delay is described as the maximum theoretical delay (see p. 482). ${ }^{1}$

We agree with Professor Mortimer that it is currently not possible to predict which patients will have treatment-refractory illness or will respond to clozapine, although the development of pathophysiologically specific markers may enable this. ${ }^{3-6}$ Likewise, we agree with Professor Mortimer that clozapine is not the only option for treatment resistance, although it has the best evidence base and this is reflected in its pre-eminence in treatment guidelines. However, we found that over a third of patients had received antipsychotic polypharmacy, and a third had received high-dose antipsychotic treatment prior to clozapine treatment. ${ }^{1}$ This indicates that poorly evidenced strategies are commonly used in preference to clozapine and, to echo Professor Mortimer, this is a disservice to our patients.

\section{Declaration of interest}

O.D.H. has been on the speaker bureaux and/or received investigator-initiated charitable research funding from AstraZeneca, Bristol-Myers Squibb, Eli Lilly, and Jansenn-Cilag. D.T. has received consultancy fees, lecturing honoraria and/or research funding from AstraZeneca, Janssen-Cilag, Servier, Sanofi-aventis, Lundbeck, Bristol-Myers Squibb, Novartis, Eli Lilly, and Wyeth.

1 Howes OD, Vergunst F, Gee S, McGuire P, Kapur S, Taylor D. Adherence to treatment guidelines in clinical practice: study of antipsychotic treatment prior to clozapine initiation. Br J Psychiatry 2012; 201: 481-5.

2 Agid O, Remington G, Kapur S, Arenovich T, Zipursky RB. Early use of clozapine for poorly responding first-episode psychosis. J Clin Psychopharmacol 2007; 27: 369-73.

3 Howes O, Bose S, Turkheimer F, Valli I, Egerton A, Stahl D, et al. Progressive increase in striatal dopamine synthesis capacity as patients develop psychosis: a PET study. Mol Psychiatry 2011; 16: 885-6.

4 Howes OD, Bose SK, Turkheimer F, Valli I, Egerton A, Valmaggia LR, et al. Dopamine synthesis capacity before onset of psychosis: a prospective [18]-DOPA PET imaging study. Am J Psychiatry 2011; 168: 1311-7.

5 Bose SK, Turkheimer FE, Howes OD, Mehta MA, Cunliffe R, Stokes PR, et al. Classification of schizophrenic patients and healthy controls using [18F] fluorodopa PET imaging. Schizophr Res 2008; 106: 148-55.

6 Demjaha A, Murray RM, Kapur S, Howes OD. Dopaminergic function in treatment resistant schizophrenia. Schizophr Bull 2011; 136 (suppl 1): S137.

Oliver D. Howes, Institute of Psychiatry, De Crespigny Park, London SE5 8AF, UK. Email: oliver.howes@kcl.ac.uk; Siobhan Gee, Pharmacy Department, Maudsley Hospital, London; David Taylor, Institute of Psychiatry, London, UK

doi: 10.1192/bjp.202.3.238a 